\title{
Possible Mechanisms of Naphthalene Toxicology: Concerning Inherited G6PD Deficiency
}

\author{
Muhammad Torequl Islam* \\ Department of Pharmacy, Life Science Faculty, Bangabandhu Sheikh Mujibur Rahman Science \& Technology University, Gopalganj-8100, Bangladesh.
}

Submission: January 10, 2018; Published: August 15, 2018

*Corresponding author: Muhammad Torequl Islam, Department of Pharmacy, Life Science Faculty, Bangabandhu Sheikh Mujibur Rahman Science \& Technology University, Gopalganj-8100, Bangladesh, Email: rbiotufpi.br@gmail.com

\begin{abstract}
Naphthalene, a main ingredient in the traditional mouthballs is reported to cause various health problems, including hemolytic anemia, diarrhea, some neurological diseases and even cancer. This article aims to depict possible mechanisms of naphthalene-induced symptoms and diseases in human and other animals. Naphthalene may act through induction of oxidative stress and inflammatory pathways along with the alterations of some important cellular biochemicals such as gamma amino butyric acid, hemoglobin, glutathione and malondialdehyde. Sufficient measures should be taken to naphthalene exposure or consumption of naphthalenated products.
\end{abstract}

Keywords: Aromatic compounds; Glucose-6-phosphate dehydrogenase; Toxicity

Abbreviations: G6PD: Glucose-6-Phosphate Dehydrogenase; Hb: Hemoglobin; HCT: Hematocrit; NADP: Nicotinamide Adenine Dinucleotide Phosphate; RBCs: Red Blood Cells; ROS: Reactive Oxygen Species; GPx: Glutathione Peroxidase; $\mathrm{H}_{2} \mathrm{O}_{2}$ : Hydrogen Peroxide; WBCs: White Blood Cells; GABA: Gamma-Aminobutyric Acid; CNS: Central Nervous System; Aß: Amyloid Beta; CRTZ: Chemoreceptor Trigger Zone

\section{Introduction}

Naphthalene $\left(\mathrm{C}_{10} \mathrm{H}_{8}\right)$, the simplest polycyclic aromatic hydrocarbon consists of a fused pair of benzene rings. It is used as a main ingredient of traditional mothballs. Generally, it is used as a precursor to other chemicals. It is used as a synthetic aid of synthetic dyes, dyestuffs, pigments, rubber processing chemicals and other chemicals as well as pharmaceuticals [1]. Naphthalene derivatives are also used in the manufacture of polymer plasticizers (dispersants), helpful to produce concrete and plasterboard (wallboard or drywall), as dispersants in synthetic and natural rubbers, and as tanning agents in leather industries, pesticides, dyes and lead-acid battery plates. Molten naphthalene is used as a solubilizing agent of poorly soluble aromatic compounds and as an effective nondetergent wetting agent for colloidal systems in aqueous media [2,3].

However, the best use of naphthalene is as a household fumigant, as it can repel some animals, insects and opossums; control pests. Literature reviews suggest that, naphthalene exposure (acute and chronic) causes some general to serious health problems, such as nausea, vomiting, diarrhea, fatigue, lack of appetite, restlessness, pale skin, confusion, bloody urination, hemolytic anemia and jaundice [4]. Exposure to naphthalene vapors evident to cause carcinogenesis, especially in lung and brain [5]. It is a Group IIB type carcinogen [6]. Acute exposure of naphthalene can cause cataracts in human and rodents.
According to the California's Proposition 65, naphthalene can cause cancer in human and other animals (Proposition 65).

Approximately 400 million people worldwide are deficient in glucose-6-phosphate dehydrogenase (G6PD). In recent years, naphthalene-exposure mediated damage or destroy red blood cells are thought to be linked in G6PD deficient patients [7]. In a recent study, a positive co-relation between 1- and 2-hydroxynaphthalene urinary metabolites and hemoglobin (Hb) and hematocrit (HCT) in non-Hispanic White, non-Hispanic Black, and Mexican-American adults in the US have been observed [8].

US government agencies have set occupational exposure limits for naphthalene exposure within 10 to $15 \mathrm{ppm}$ (50 to $75 \mathrm{mg} / \mathrm{m}^{3}$ ) [9], while European Union have been banned using mouthballs containing naphthalene since 2008 [10]. In China, the use of naphthalene in mothballs is forbidden. In Bangladesh, naphthalene is vastly used as a fumigant. This article aims to sketch possible toxicological action mechanisms of naphthalene, especially in this type of patients.

\section{Possible mechanisms of naphthalene toxiclogy}

G6PD reduces nicotinamide adenine dinucleotide phosphate $\left(\mathrm{NADP}^{+}\right)$to NADPH during oxidizing glucose-6-phosphate (G6P) [11], that involves in the biosynthesis of fatty acids or 
isoprenoids, especially in the liver, mammary glands, adipose tissue, and the adrenal glands. In general, this enzyme catalyzes the first step in the pentose phosphate pathway to generate NADPH which maintains the level of glutathione in these cells that helps to protect the red blood cells (RBCs) against oxidative damage from reactive oxygen species (ROS). These ROS can cause damage of cellular macromolecules (e.g. - carbohydrates, proteins, lipids, as well as genetic materials such as DNA, RNA).

Glutathione, an important antioxidant in plants, animals, fungi, and some bacteria and archaea is capable of preventing cellular components damage caused by ROS such as free radicals, peroxides, lipid peroxides, and heavy metals [12]. Glutathione plays an important role in preventing oxidative stress in human cells, via scavenging hydroxyl radicals, singlet oxygen, and various electrophiles. GSH reduces the oxidized form of the enzyme glutathione peroxidase (GPx), which in turn reduces $\mathrm{H}_{2} \mathrm{O}_{2}$ to water and molecular oxygen, ameliorating oxidative stress in cells, including RBCs. Although, hydrogen peroxide $\left(\mathrm{H}_{2} \mathrm{O}_{2}\right)$ like other ROS plays a key role in the immune system. Scientific reports suggest that in large amount of $\mathrm{H}_{2} \mathrm{O}_{2}$ exerts damaging effects of proteins and lipids, thereby causing intravascular RBC lysis and/or extravascular RBC clearance by macrophages in the reticulo-endothelial system [13]. An inappropriate level of white blood cells (WBCs) can accumulate $\mathrm{H}_{2} \mathrm{O}_{2}$ in the lung of asthmatic patients [14], which may cause excessive tissue damage in this category patients. Moreover, excessive production of $\mathrm{H}_{2} \mathrm{O}_{2}$ is evident for cellular aging [15] and development of cancer [16].

Certain oxidative substances, including medications can cause hemolysis in G6PD-deficient individuals by inducing oxidative stress. In Tribolium castaneum, the lethal concentration $50\left(\mathrm{LC}_{50}\right)$ for naphthalene was found $63.6 \mu \mathrm{L} / \mathrm{L}$, which was less than naphthal but more than two times higher than benzene [17]. It was also demonstrated that the naphthalene inhalation are able to induce oxidative stress along with the alterations in reproduction, development, metamorphosis, metabolism, neurotransmission, and death of the insect. Naphthaleneinduced oxidative stress was also reported by Huang et al. [18] where naphthalene at $500 \mathrm{mg} / \mathrm{kg}$ for $60 \mathrm{~d}$ significantly increased the production of $\mathrm{H}_{2} \mathrm{O}_{2}$ and malondialdehyde (MDA) by Trifolium repens.

Generally, ROS degrade polyunsaturated lipids and form MDA [19], which subsequently reacts with deoxyadenosine and deoxyguanosine in DNA and forms DNA adducts, the primary one being M1G, which is mutagenic [20]. It has been reported that in an established tumor, elevated levels of glutathione can protect cancerous cells by conferring resistance to chemotherapeutic drugs [21]. Thus, an alteration in glutathione levels may not only relates to the development of oxidative stress-mediated diseases but also anticancer drug resistance.

Moreover, glutathione can activate the purinergic P2X7 receptor from Müller glia, inducing acute calcium transient signals and causes the release of gamma-aminobutyric acid
(GABA) from both retinal neurons and glial cells [22]. GABA, the chief inhibitory neurotransmitter in the mammalian central nervous system (CNS), which is responsible to reduce neuronal excitability [23]. GABA at high levels exerts relaxing, antianxiety, and anti-convulsive effects [24]. Thus an inhibition of glutathione may link to the GABAergic occurance of restlessness, anxiety and convulsion in the animals.

GABAergic mechanisms have been also reported in various peripheral tissues and organs, including intestines, stomach, pancreas, Fallopian tubes, uterus, ovaries, testes, kidneys, urinary bladder, lungs, and liver [25]. An excitatory GABAergic system has been found in the airway epithelium, which can be activated by the exposure of allergens, possible participants in the mechanisms of asthma [26]. Moreover, GABAergic systems have also been found in the testis [27] and in the eye lens [28]. It is also indicated that, GABA is a primarily excitatory neurotransmitter in the developing brain [29]. In a study, it was suggested that orally administered GABA increased the amount of human growth hormone [30]. It seems, naphthelene exposure during the pregnancy or earlier stages can affect the overall development in animals.

The extracellular amyloid beta $(A \beta)$ plaques, neurofibrillary tangles, inflammation in the form of reactive astrocytes and microglia, and neuronal loss are all consistent pathological features of Alzheimer's disease. The soluble oligomeric $A \beta$ species are now considered to be of major pathological importance in this important neurological diseases. Down-regulation of GSH may induce the oxidative stress and neurotoxic effects of oligomeric $\mathrm{A} \beta$. Memory loss and confusion are the main symptoms in AD. On the other hand, a change in the brain's electrical activity is a major cause of seizures. Naphthalene may affect these pathways.

Nausea, a feeling of vomiting, while vomiting is an uncontrollable reflex that expels the contents of the stomach through the mouth. They may occur together or separately. Ingestion or exposure of a variety of substances, including noxcious aromatic compounds can lead to these symptoms. The vomiting center activates directly by the irritants or indirectly through four principal areas: gastrointestinal tract, cerebral cortex and thalamus, vestibular region, and chemoreceptor trigger zone (CRTZ). The CRTZ, closest in proximity, lying between the medulla and the floor of the fourth ventricle is not protected by the blood-brain barrier which permits irritants regardless of their lipid solubility or molecular size [31].

Diarrhea can cause dehydration and electrolyte imbalance due to fluid and electrolyte loss. Inflammatory diarrhea, among the other types, occurs when there is damage to the mucosal lining or brush border, that leads to a passive loss of proteinrich fluids and a decreases the ability to absorb these lost fluids [32]. Inflammatory bowel diseases can cause simple diarrhea or bloody diarrhea. Antioxidants and antiinflammatory agents can be used to treat these kinds of diseases, as oxidative stress and inflammation are known to occur in this case [33]. On the other 
hand, paleness is caused by reduced blood flow and oxygen or by a decreased number of RBCs. Acute anemia due to rapid blood loss of RBCs and bleeding from the stomach or intestinal tract.

In summary, naphthalene can induce ROS and inflammation in the exposed host, thereby, causes alterations of cellular biochemistry and destroy cellular macromolecules, leading to cause many health problems, including neurodegenerative diseases and even cancer. Naphthalene-mediated reduction of RBCs and jaundice may be due to its hemolytic effects in animals. We should take sufficient measures in the use of mouthballs or direct exposure of naphthalene.

\section{References}

1. Collin G, Höke H, Greim H (2003) Naphthalene and Hydronaphthalenes in Ullmann's Encyclopedia of Industrial Chemistry, Wiley-VCH, Weinheim.

2. Komatsua K, Murataa Y, Sugitaa N, Takeuchib K, Wan TSM (1993) Use of naphthalene as a solvent for selective formation of the 1:1 Diels-Alder adduct of $\mathrm{C}_{60}$ with anthracene. Tetrahedron Lett 34(52): 8473-8476.

3. Filatov MA, Cheprakov AV (2011) The synthesis of new tetrabenzoand tetranaphthoporphyrins via the addition reactions of 4,7-dihydroisoindole. Tetrahedron 67(19):3559-3566.

4. MedlinePlus Encyclopedia Naphthalene poisoning.

5. NTP Technical Reports 410 and 500 (2004) NTP Technical Reports 410 and 500, available from NTP: Long-Term Abstracts \& Reports.

6. IARC Monographs on the Evaluation of Carcinogenic Risks to Humans (2002) Monographs on the Evaluation of Carcinogenic Risks to Humans, Some Traditional Herbal Medicines, Some Mycotoxins, Naphthalene and Styrene 82: 367.

7. Santucci K, Shah B (2000) Association of naphthalene with acute hemolytic anemia. Acad Emerg Med 7(1): 42-47.

8. Sudakin DL, Smit E, Cardenas A, Harding A (2013) Naphthalene biomarkers and relationship with hemoglobin and hematocrit in White, Black, and Hispanic adults: results from the 2003-2004 National Health and Nutrition Examination Survey. J Med Toxicol 9(2): 133-138.

9. CDC - NIOSH Pocket Guide to Chemical Hazards.

10. Gray K (2013) Council warned against use of poisonous moth balls. Your Local Guardian. Newsquest (London) Ltd.

11. Aster J, Kumar V, Robbins SL, Abbas AK, Fausto N, Cotran RS (2010) Robbins and Cotran Pathologic Basis of Disease. Saunders/Elsevier. pp. Kindle Locations 33340-33341.

12. Pompella A, Visvikis A, Paolicchi A, De Tata V, Casini AF (2003) The changing faces of glutathione, a cellular protagonist. Biochem Pharmacol 66(8): 1499-1503.

13. Thomas D, Cherest H, Surdin-Kerjan Y (1991) Identification of the structural gene for glucose-6-phosphate dehydrogenase in yeast. Inactivation leads to a nutritional requirement for organic sulfur. EMBO J 10(3): 547-553.

14. Niethammer P, Grabher C, Look AT, Mitchison TJ (2009) A tissue-scale gradient of hydrogen peroxide mediates rapid wound detection in zebrafish. Nature 459(7249): 996-999.
15. Weindruch R (1996) Calorie Restriction and Aging. Sci Am 49-52.

16. López-Lázaro M (2007) Dual role of hydrogen peroxide in cancer: possible relevance to cancer chemoprevention and therapy. Cancer Lett 252: 1-8.

17. Pajaro-Castro N, Caballero-Gallardo K, Olivero-Verbel J (2017) Toxicity of Naphthalene and Benzene on Tribollium castaneum Herbst. Int $J$ Environ Res Public Health 14(6): 667.

18. Huang Y, Huang J, Song Y, Liu H (2017) Use of selenium to alleviate naphthalene induced oxidative stress in Trifolium repens L. Ecotoxicol Environ Saf 143: 1-5.

19. Pryor WA, Stanley JP (1975) Letter: A suggested mechanism for the production of malondialdehyde during the autoxidation of polyunsaturated fatty acids. Nonenzymatic production of prostaglandin endoperoxides during autoxidation. J Org Chem 40(24): 3615-3617.

20. MarnettLJ(1999) Lipid peroxidation-DNA damage by malondialdehyde. Mutat Res 424(1-2): 83-95.

21. Balendiran GK, Dabur R, Fraser D (2004) The role of glutathione in cancer. Cell Biochem Funct 22: 343-52.

22. Freitas HR, Reis RA (2017) Glutathione induces GABA release through P2X7R activation on Müller glia. Neurogenesis 4(1): e1283188.

23. Watanabe M, Maemura K, Kanbara K, Tamayama T, Hayasaki H (2002) GABA and GABA receptors in the central nervous system and other organs. Int Rev Cytol 213: 1-47.

24. Foster AC, Kemp JA (2006) Glutamate- and GABA-based CNS therapeutics. Curr Opin Pharmacol 6(1): 7-17.

25. Erdö SL, Wolff JR (1990) $\gamma$-Aminobutyric acid outside the mammalian brain. J Neurochem 54: 363-72.

26. Xiang YY, Wang S, Liu M, Hirota JA, Li J, et al. (2007) A GABAergic system in airway epithelium is essential for mucus overproduction in asthma. Nat Med 13(7): 862-867.

27. Payne AH, Hardy MH (2007) The Leydig cell in health and disease. Humana Press.

28. Kwakowsky A, Schwirtlich M, Zhang Q, Eisenstat DD, Erdélyi F, et al. (2007) GAD isoforms exhibit distinct spatiotemporal expression patterns in the developing mouse lens: correlation with Dlx2 and Dlx5. Dev Dyn 236(12): 3532-3544.

29. Li K, Xu E (2008) The role and the mechanism of $\gamma$-aminobutyric acid during central nervous system development. Neurosci Bull 24(3): 195200.

30. Powers ME, Yarrow JF, McCoy SC, Borst SE (2008) Growth hormone isoform responses to GABA ingestion at rest and after exercise. Med Sci Sports Exerc 40(1): 104-110.

31. Becker DE (2010) Nausea, Vomiting, and Hiccups: A Review of Mechanisms and Treatment. Anesth Prog 57(4): 150-157.

32. Moon C, Zhang W, Sundaram N, Yarlagadda S, Reddy VS, et al. (2015) Drug-induced secretory diarrhea: A role for CFTR. Pharmacol Res 102: 107-112.

33. Vargas Robles H, Castro Ochoa KF, Nava P, Silva Olivares A, Shibayama M, Schnoor M (2017) Analyzing Beneficial Effects of Nutritional Supplements on Intestinal Epithelial Barrier Functions During Experimental Colitis. J Vis Exp 119. 
This work is licensed under Creative Commons Attribution 4.0 License

DOI: 10.19080/JCMAH.2018.06.555695
Your next submission with Juniper Publishers will reach you the below assets

- Quality Editorial service

- Swift Peer Review

- Reprints availability

- E-prints Service

- Manuscript Podcast for convenient understanding

- Global attainment for your research

- Manuscript accessibility in different formats

( Pdf, E-pub, Full Text, Audio)

- Unceasing customer service

Track the below URL for one-step submission https://juniperpublishers.com/online-submission.php 